\title{
Modelo de gestión para los centros de turismo comunitario del cantón Archidona
}

\author{
Management model for community tourism centers in the Archidona canton \\ Lenin Diego Shiguango Shiguango. ${ }^{1}$, Clímaco Geovani Espín Ortíz. ${ }^{2}$, Juan José Olivo \\ Pesántez. ${ }^{3}$ \& Mayra Inés Pinta Rodríguez. ${ }^{4}$
}

\begin{abstract}
.
Introduction. Community tourism is a relatively young option for the third sector of the economy, a modality recognized for its contributions to the development of countries located in Latin America, Africa and Asia; made up of a social fabric of native and peasant communities respectively. Expectations of rurality that are being calculated and oriented to generate complementary options to the local daily work. However, it implies addressing the current problem that community managers who show technical limitations when managing this type of company in the territory; for which the objective of the research is to propose a management model with a complementary approach suitable for community tourism centers, Archidona canton. Methodology. The research design used was a descriptive analysis, based on the state of the art, information that I guide to fulfill the following phases: 1.- Diagnosis of three (3) tourist centers Santa Rita, Amarun Pakcha and Sacha Wayusa. 2.- Structure a management model articulating the three (3) tourist centers and 3.- Assessment of the community management model, a tool that could be

\footnotetext{
${ }^{1}$ Universidad Estatal Amazónica, Centro de Posgrado, Maestrante en Turismo, Mención Gestión del Turismo, dlenin49@gmail.com, https://orcid.org/0000-0001-7491-775X, Puyo-Ecuador

${ }^{2}$ Universidad Estatal Amazónica, Facultad Ciencias de la Vida, Carrera de Turismo, cespin@uea.edu.ec: https://orcid.org/0000-0001-5047-4704, Puyo-Ecuador

${ }^{3}$ Gobierno Autónomo Descentralizado del cantón Pastaza, Dirección de Turismo, juanolivop@ gmail.com, https://orcid.org/0000-0002-7769-6865, Puyo-Ecuador

4 Universidad Estatal Amazónica, Centro de Posgrado, Coordinación Maestría en Turismo mpinta@uea.edu.ec, https://orcid.org/0000-0002-8285-538, Puyo-Ecuador
} 
implemented as an intervention strategy to strengthen the knowledge of the local manager. Results. The three resorts have a weighted Endogenous MEFI value of 2.52 and Exogenous MEFE of 2.53, claiming that the average value is 2.50 according to the variables of the SWOT matrix. The management model with a complementary approach links to community tourism sustainability in Archidona place; tool, which can contribute to overcoming community / tourist limitations ordered work based on the variables that make up the proposal: Philosophical, Strategic, Tactical, Operational and Evaluative. Finally, the evaluation of the experts on the proposal with a complementary approach according to the benefits of each territory, determined: the final evaluation of the IOR is 0.93 / 100 of high applicability.

Keywords. - Community tourism, management model and tourism complementarity

\section{Resumen}

Introducción. El turismo comunitario una opción relativamente joven del sector tercero de la economía, modalidad reconocida por sus aportes al desarrollo de países localizados en Latinoamérica, África y Asia; conformado por un tejido social de comunidades originarias y campesinas respectivamente. Expectativas de ruralidad que se están cifrando y orientando para generar opciones complementarias al laboreo diario local. Sin embargo, implica abordar la problemática actual que los gestores comunitarios que evidencian limitaciones técnicas al momento de gestionar este tipo de empresas en territorio; para lo cual el objetivo de la investigación es proponer un modelo de gestión con enfoque de complementariedad adecuado para los centros de turismo comunitario, cantón Archidona. Metodología. El diseño de investigación utilizada fue un análisis descriptivo, partiendo del estado del arte, información que oriento para cumplir las siguientes fases: 1.Diagnostico de tres (3) centros turísticos Santa Rita, Amarun Pakcha y Sacha Wayusa. 2.- Estructura un modelo de gestión articulando los tres (3) centros turísticos y 3.Valoración del modelo de gestión comunitario, herramienta que pudiera ser implementada como estrategia de intervención para fortalecer el conocimiento del gestor local. Resultados. Los tres centros turísticos poseen un valor ponderado Endógeno MEFI de 2,52 y Exógeno MEFE de 2.53 reclacando que el valor dela media es de 2.50 de acuerdo a las variables de la matriz DAFO. El modelo de gestión con enfoque de complementariedad vincula a la sostenibilidad turística comunitaria en el Catón Archidona; herramienta, que puede contribuir a superar las limitaciones comunitarias / Turísticas trabajo ordenado a partir de las variables que componen la propuesta: Filosófico, Estratégico, Táctico Operativo y Valorativo. Finalmente, la valoración de los expertos sobre sobre la propuesta con enfoque de complementariedad de acuerdo a las bondades de cada territorio, determino: la valoración ultima del IOR es del 0.93/100 de alta aplicabilidad.

Palabras Claves. - Turismo Comunitario, modelo de gestión y complementariedad turística 


\section{Introducción}

En las últimas décadas, la industria turística en el Ecuador paso a ser una de las principales actividades en el reducto de la economía, representando el $22 \%$ del producto interno bruto (PIB), generando ingresos por turismo receptor de 2.287,5 millones de dolores (Ministerio de turismo, 2020). Es así, que el País con sus cuatro mundos naturales abarca una gran diversidad y endemismo que provoca que los clientes/turistas/visitantes contemporáneos (formados e informados) buscan experimentar nuevas formas para el descanso, la diversión y el desarrollo personal en sitios relacionales directamente con los patrimonios. Esta nueva forma de hacer turismo tiene un enfoque de territorialidad que asocia principalmente a la ruralidad comunitaria, siempre y cuando la salud de los anfitriones y turistas no esté en riesgo.

El turismo comunitario surge como una alternativa económica de las comunidades rurales, campesinas, indígenas, mestizas y afrodescendientes propias de un país, para generar ingresos complementarios a las actividades económicas diarias para defender y revalorizar los recursos culturales y naturales. El Ecuador es uno de los países más desarrollados y reconocidos en el ejercicio del Turismo Comunitario. Cuenta con cerca de cien (100) experiencias y otro tanto en proceso de formación. Todas ellas situadas a lo largo de su territorio, y que se encuentran desde el nivel del mar hasta los $4000 \mathrm{msnm}$. Emprendimientos auto realizados por las propias comunidades; cabe mencionar, que el sector público y privado se han mantenido al marguen salvo ciertos casos muy puntuales. (FEPTCE, 2017)

El cambio acelerado que se está manifestando en la toma de decisiones de los turistas en los últimos tiempos; y, más aún con la situación emergente como es el COVID-19, muchos gestores turísticos de los sectores: público, privado y principalmente comunitario se ven en la necesidad de actualizar e innovar sus productos con un enfoque de sostenibilidad relacionando con el bienestar de todos. (Sanda \& Rojas , 2020)

En este contexto, el turismo comunitario es una aspiración de las nacionalidades y pueblos que se constituyen en las comunidades de la Amazonia Ecuatoriana, en especial las que son parte del Cantón Archidona; a fin de, conservar y aprovechar racionalmente los activos ambientales y sociales. Es así, que han emergiendo emprendimientos de turismo comunitario en territorio de esta jurisdicción, en base a los conocimientos empíricos, lo que está limitando con facilidad el desarrollo de estas iniciativas.

El desarrollo del turismo comunitario en Archidona: comunidades "Santa Rita, Amarun Pakcha y Sacha Wayusa"; carece de un modelo de gestión, acción que limita a estas comunidades optar por actividades que pudieran diversificar la economía de sus habitantes. 
El objetivo de esta investigación fue: establecer un "Modelo de gestión para los centros de turismo comunitario del cantón Archidona", que sirva de base para desarrollar conocimientos de los gestores locales en el área de administración a partir del fortalecimiento de las capacidades en planeación, organización, operación y valoración de este tipo de emprendimiento; con enfoque a los principios de la complementariedad competitividad; y así, poder facilitar el uso práctico, desde la estructura turística comunitaria y los rasgos distintivos de Archidona.

\section{Marco referencial}

\section{Turismo comunitario}

El turismo es ante todo un potente factor transformador del territorio. En todo el continente ha dado lugar a una producción histórica y contemporánea de instalaciones especializadas que explica la diferenciación y la diversificación de toda una tipología de espacios turísticos. En un proceso como este, existen tres dimensiones que merecen una atención especial: las condiciones de la apertura al turismo en territorio, el proceso de desarrollo del turismo a largo liento y las consecuencias territoriales de la implantación de la actividad. (Boussut et Elodie Salin, 2018).

Las américas en la actualidad se ha constituido como el tercer destino a nivel mundial, superado por Europa y Asia del Pacifico, el turismo en estos destinos según el barómetro de la OMT, (2018) registró las llegadas de turistas internacionales crecieron un $6 \%$ en 2018, llegando a los 1.400. El pronóstico a largo plazo de la OMT publicado en 2010 indicaba que se alcanzarían los 1.400 millones en año 2020, pero el notable crecimiento de las llegadas internacionales en los últimos años se ha adelantado por dos años.

En este contexto, el turismo comunitario, si bien es percibido como un motor de desarrollo económico y social en territorios rurales, corresponde más bien a una corriente de pensamiento surgida a finales de la década de los 90`s llamada «turismo pro-pobre» (Figueroa Pinedo, 2014). Al generar accesibilidad, oportunidades y empleo en espacios rurales menos favorecidos, esta modalidad puede desencadenar una nueva conciencia en favor de la diversidad cultural, conservando y provechando adecuadamente los patrimonios. (Espin, 2019).

Muchos espacios geográficos rurales con limitaciones económicas, desempleo y reducidos ingresos de sus habitantes, están apostando por una alternativa denominada TURISMO COMUNITARIO, que en su definición denota: "turismo a través del cual la población local busca mejorar su situación socio-económica conservando los recursos naturales del territorio mediante el contacto establecido entre la comunidad local y el visitante, donde éste interactúa con las organizaciones que prestan el servicio, con el entorno donde se desarrolla la actividad y su contexto" criterios coincidentes de autores tales como (Maldonado, 2005); (Morgado, 2006); (López-Guzmán \& Sancho, 2006); 
(López-Guzmán \& Sánchez, 2009); (Trejos, 2009); (Henríquez et al., 2010); (Del Barco, 2010); (Pacheco et al.,2011); (Olivera et al., 2012); (Casas, 2012) \& (Orgaz 2013) \& (Reyes, Ortega, \& Machado, 2017)

Por lo tanto el turismo comunitario evoluciono como una estrategia para el desarrollo sostenible territorial, debido a que este en su concepción establece la auto-gestión de la actividad por parte de los habitantes locales y por ende un control de los beneficios que se generen por concepto del mismo, por lo que constituye una nueva forma de desarrollo a partir que la cultura y el patrimonio local, es utilizado por las propias comunidades (Orgaz, 2013) \& (Reyes, Ortega, \& Machado, 2017)

Citado por (Henríquez et al., 2010) \& (Reyes, Ortega, \& Machado, 2017), el turismo comunitario se apoya en cuatro (4) componentes principales:

- Comunidad. - Se percibe en la sociedad positivamente pues significa calidez, confortabilidad y acogedor, lo que provoca seguridad y confianza.

- Convivencialidad. - Observa cómo relación social donde uno se interesa por el otro, por el respeto a la forma de vida e idiosincrasia (mismidad); la interrelación que se produce entre habitantes y foráneos, posibilita la inter-conectividad entre modos diferentes de vida.

- Laboreo diario. - Identifica aspectos relacionales de las personas, el uso del tiempo y el espacio, las formas de organizar el trabajo, las formas simbólicas y los medios de comunicación, y tecnologías adaptadas por estas poblaciones en su realidad diaria

- Autonomía económica. - Incorpora los términos económicos desde una visión de rentabilidad con enfoque de autonomía e independencia, lo que pudiera enfocar un aporte a la sostenibilidad del tejido social local

Esta modalidad de Turismo, como otras tantas, se puede ejecutar en territorios rurales prístinos o no; gestionado por las propias comunidades originarias, campesinas u otras. Integrando a su territoriedad acciones foráneas que complementan su laboreo diario. Muchas sociedades locales tienden a ejecutar actividades turísticas de acuerdo con su bondades geográficas y perfiles culturales como: turismo de naturaleza, ecoturismo, turismo vivencial, etno-turismo, agro-turismo, turismo alternativo, turismo seguro... (FEPTCE, 2017); (Reyes, Ortega, \& Machado, 2017) \& (Espin, 2019).

A manera de síntesis, el turismo comunitario "contemporáneo" para ser parte de un territorio; en primer lugar, debe brindar confianza de seguridad a la salud de todos los actores turístico desde el momento cero de la verdad; en segundo lugar, generar beneficios económicos que diversifique la economía de los gestores y familias locales; y, en tercer lugar, debe proteger los patrimonios. (Gascón \& Cañada, 2005) \& (Shiguango, 2020). El cumplimento de esta trilogía, al turista que, a partir del desarrollo de esta modalidad, 
pueden vivir experiencias relacionadas con otras culturas y entrar en contacto con la naturaleza y sus paisajes, participando en los procesos productivos y conociendo culturas diversas. Se convierte en un catalizador Se convierte en un catalizador de la búsqueda de actividades económicas compatibles con la conservación ambiental, y aún supone una exploración consistente de condiciones más equilibradas para el encuentro de diferentes sociedades, se podría enfocar al tan anhelado "turismo sostenible" gestiona desde la ruralidad. (Maldonado \& Hernadez, 2017)

La pregunta obligada a nivel mundial, nacional y local es: ¿Cómo promover el turismo comunitario sostenible?; para aquello es importante considerar los siguientes aspectos, (Shiguango, 2020):

- Viabilidad económica de las empresas comunitarias

- Realización de los recursos humanos que participan en la actividad turística, es decir que se sientan satisfechos por lo que hacen y por los beneficios que reciben

- Bienestar de la población anfitriona

- Valoración de la identidad cultural de la población

- Protección de los diversos ecosistemas de las comunidades

- Clientes totalmente satisfechos en función de las 3 " $\mathrm{D}$ " del turismo; Descanso Diversión y desarrollo personal.

- Bioseguridad "salud" del cliente en territorio

Figura 1. Como promover el turismo comunitario con espíritu de sostenibilidad

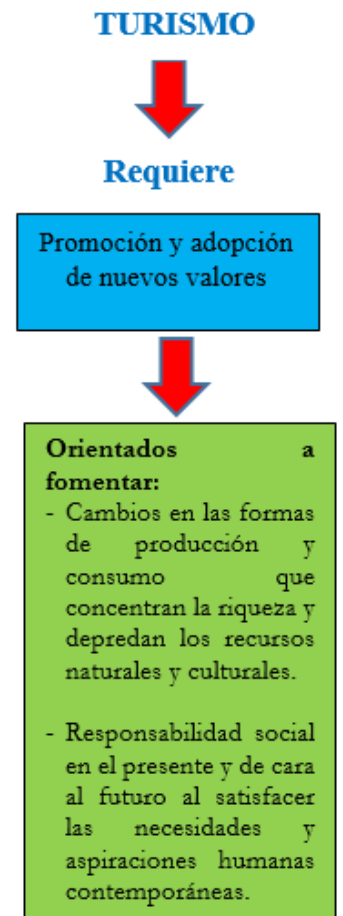

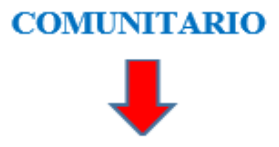

Exige

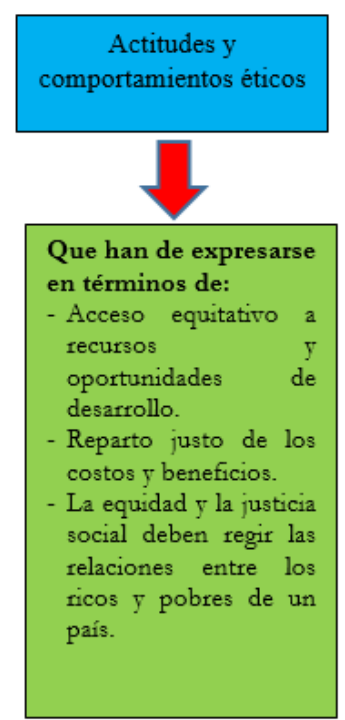

SOSTENIBLE

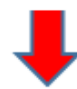

Implica

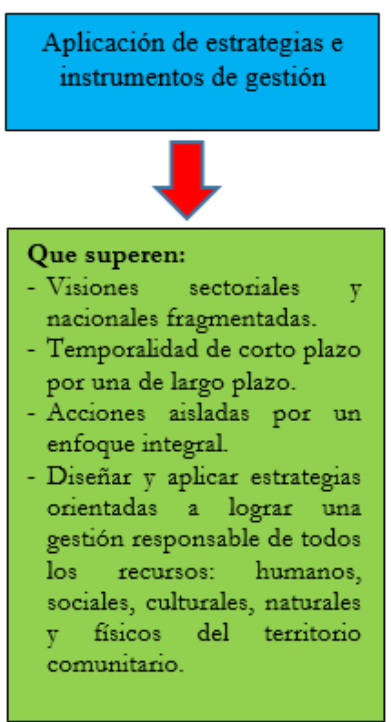

Fuente: Elaboración propia a partir de Maldonado \& Hernadez, (2017). 


\section{Turismo comunitario en el Ecuador}

Esta modalidad, ha sido analizada por una gran cantidad de investigadores, docentes y profesionales de diferentes áreas de las ciencias sociales a nivel del mundo y en Ecuador no es la excepción. Las iniciativas exitosas y las no tanto, han experimentado trasformaciones antrópicas de los territorios con el único fin de generar espacios turísticos en base al aprovechamiento los patrimonios, este auto-uso racional en calidad de herramienta esta direccionada al objetivo de desarrollo sostenible (ODS) No. 1. Fin de la pobreza. (ONU, 2015)

Para contextualizar el turismo comunitario en el país, es importante evidenciar que en América del Sur / Latinoamérica ha desarrollado eventos de alcance regional con el objetivo de debatir y concertar estrategias de promoción, mercadeo y comercialización de productos turísticos comunitarios para deliberar y proponer directrices que permitan establecer códigos de conducta, con el objeto de preservar la identidad cultural y la autenticidad de los destinos turísticos comunitarios; uno de los eventos más trascendentales fue organizado por el Instituto Costarricense de Turismo-ICT y la Comisión Nacional de Asuntos Indígenas-CONAI, que tuvo lugar en San José, Costa Rica en octubre de 2003, en el cual participaron representantes de organizaciones comunitarias y cooperativas turísticas de Perú, Costa Rica, Bolivia, Brasil, Guatemala y Ecuador.

El acuerdo de este encuentro fue, "Declaración de San José sobre turismo rural comunitario", la Organización Internacional de Trabajo incorpora elementos clave en la definición del turismo comunitario como es el anhelo para que las comunidades logren, a partir del turismo "prosperar y vivir dignamente", con optimización de sus situaciones de vida y de trabajo y una justa "distribución de los ingresos", todo lo cual hará del turismo una actividad "socialmente solidaria, ambientalmente responsable, culturalmente enriquecedora y económicamente viable" en condiciones saludables de quienes participan. (Moragues Cortada, 2006); (Reyes, Ortega, \& Machado, 2017) \& (Shiguango, 2020).

Tabla 1. Turismo Comunitario, experiencias Latinoamericanas declaración de San José

País / Países

Perú y Bolivia

Costa Rica

\section{Experiencia}

Destaca el trabajo en conjunto que se ha desarrollado entre las comunidades, empresas privadas y municipios, se evidencia la participación junto a las comunidades de grupos privados y la dirección de los municipios, sin embargo, se señala como insuficiencias la carencia de participación de representantes del ministerio a cargo del turismo; lo que constituye uno de los principales problemas que enfrentan los actores relacionados con el turismo.

Plantea el aprovechamiento de la riqueza natural hacia una visión de carácter social hasta llegar a convertirse en una de los países de Latinoamérica que más ha potenciado el turismo rural comunitario, el 
mismo se ha articulado alrededor de dos redes: la Red Ecoturística Nacional y la Asociación Comunitaria de Turismo Rural, las cuales desarrollan programas de apoyo, promoción y formación dirigidos a las asociaciones que las conforman

Brasil

Viene desarrollando TC, desde el año 2006, bajo una metodología educativo-participativa, basada en la investigación-acción, mediante la sociedad entre comunidades e instituciones públicas, a partir de impulsar el cooperativismo

Guatemala

La práctica del TC, se asocia al rescate de la identidad maya y a la presencia de áreas boscosas protegidas por grupos indígenas, por medio de parcialidades, lo cual se refiere a aquellos grupos sociales indígenas que poseen una extensión variable de tierra en común, estas organizaciones presentan características particulares, sustentadas en su identidad étnica

Fuente: Elaboración propia a partir de (Nel-Lo, 2008); (Trejos,2009); (Sepúlveda et al., 2010); (Pacheco et al., 2013); (Sánchez \& Victorino, 2015); (Livera et al. 2016); (De Olivera et al., 2017); (Reyes, Ortega, \& Machado, 2017) \& (Quishpe-Quishpe, 2019)

En el país de los cuatro mundos los principales recursos y atractivos están localizados en territorios rurales principalmente en áreas prístinas que son parte de las nacionalidades y pueblos originarios, lugares alejados de las grandes urbes; mismos, que se caracterizan por poseer índices pobreza altos, acción que se puede evidenciar por el limitado acceso a los servicios básicos, esporádicas oportunidades para fortalecer sus capacidades y aculturización permanente. Lugares, que el turismo comunitario puede representar verdaderas opciones de desarrollo local con enfoque sostenible, distintivo actual que permite la generación y gestión de productos contemporáneos. (Espin, 2019)

En el Ecuador las Comunidades, y por ende las operaciones de Turismo Comunitario que los representan, se agrupan dentro de la Federación Plurinacional de Turismo Comunitario del Ecuador "FEPTCE", organismo gremial representativo de esta actividad en este país. Está estructurada con representantes de todas las comunidades involucradas a nivel regional, provincial y local, en donde destaca la Red de Turismo Comunitario del Austro Pakariñan (Camino del Amanecer, en lengua Kañari), que aglutina a todo el sur del Ecuador. Además, en la costa de Ecuador está la comunidad de Salango. (FEPTCE, 2012) \& (Ordóñez, Auquilla, Fernández, \& Sancho, 2016)

El Turismo comunitario en el País, se ha caracterizado como motor estratégico para el desarrollo y la promoción socioeconómica de comunidades en situaciones muy vulnerable, el cual ha potenciado las identidades culturales indígenas y su contacto intercultural a través del turismo, y ha permitido desarrollar actividades económicas sostenible desde el punto de vista ambiental, así como la apertura de posibilidades de una gestión propia en las comunidades indígenas. (Ruiz, Solís 2007), (Ruiz 2011) \& (Cabanilla, (2014) 
El turismo tiene bien marcados las temporadas durante el año, así las temporadas altas se registran los meses de (julio, agosto, diciembre) y muy bajas (marzo, abril, septiembre). En TC, esta estacionalidad constituye una fortaleza ya que se aprovechan las temporadas altas de arribo de visitantes durante el mes de agosto, donde los comuneros se encuentran libres de sus actividades cotidianas (laboreo diario) y listos para recibir a los visitantes generando una ocupación temporal y/o permanente en la comunidad. Además, TC promueve la equidad de género, al integrar las mujeres en su estructura laboral en un 51\%, es decir la relación laboral de género cumple la propuesta del programa impulsada por la Organización Naciones Unidas (ONU) Turismo Sostenible y Fin de la Pobreza. Promover la igualdad de género y el empoderamiento de la mujer. (OMT, 2014) \& (ONU, 2015).

Según las estadísticas de la Federación Plurinacional del Turismo Comunitario, la modalidad de TC se ha desarrollado en los Andes con un 70\%, la Amazonía con el 20\% y el $10 \%$ en la Costa del Pacífico. Demostrando un crecimiento promedio anual en el orden del $3 \%$. En base a la diversidad biológica y cultural, constituyendo una alternativa de desarrollo económico simbiótico en territorio.

\section{Gráfico 1. Turismo comunitario en el Ecuador, porcentaje ponderado}

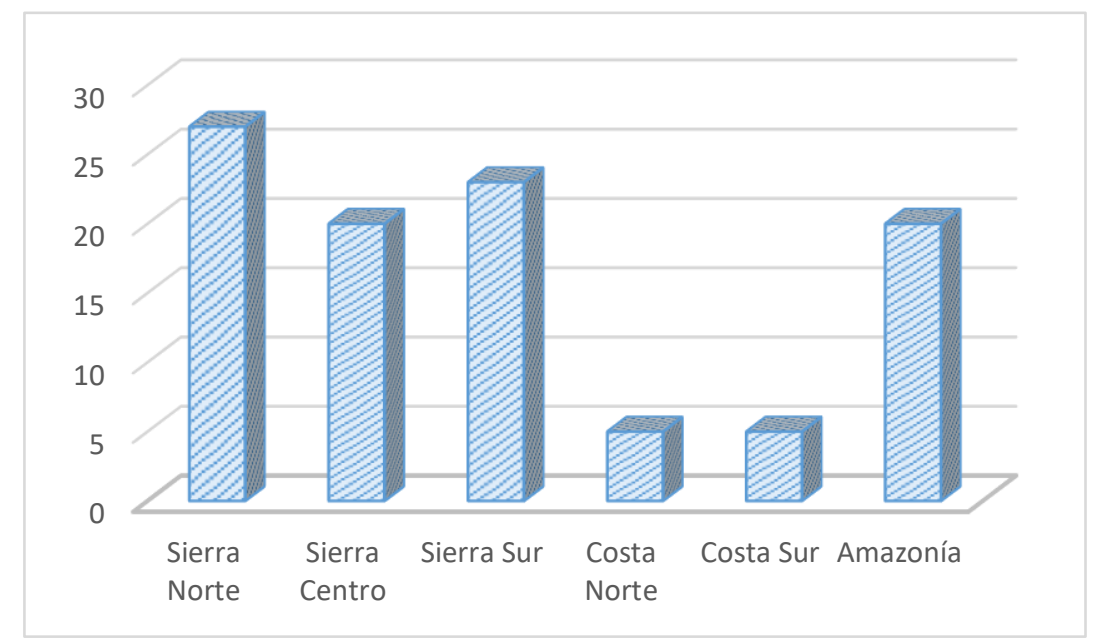

Fuente: Elaboración propia a partir de (Vargas-Cumbajín, Yánez-Sego, Hernadéz-Benalcázar, MéndezJátiva, \& Valdiviezo-Leroux, 2019)

Un componente a considera de importancia para el funcionamiento del Turismo Comunitario "TC" en Ecuador se encuentra regulado por la Ley y sus reglamentos. El reconocimiento del turismo comunitario como un sector más de la actividad turística fue incorporado en la Ley de Turismo del Ecuador (Ley de Turismo $N^{\circ}$ 97, 2002) tras un esfuerzo y diálogo de 25 años entre las comunidades y el Estado. Esta Ley, en su Capítulo II, "De las Actividades Turísticas y de Quienes las Ejercen”, Artículo 12. Así mismo en el Articulo 5.- De la Gestión.- La gestión de la actividad turística corresponde a la comunidad, y como tal se procederá a su Registro en el Ministerio de Turismo, previo al inicio de su funcionamiento" (Reglamento para los Centros Turísticos Comunitarios 2010); al preguntar su condición jurídica en cuanto a su legalización en calidad CTC, a 
decir de (Vargas-Cubajín, 2019) el 62\% están legalizados, un 33\% están en trámite y un $5 \%$ admite no está legalizado, evidenciando el lado positivo en el ámbito reglamentario.

Para la Federación Plurinacional de Turismo Comunitario del Ecuador, FEPTCE, el turismo comunitario debe ser una actividad sostenible, que genere beneficios económicos para las comunidades involucradas, que contribuya a la conservación de la herencia natural y al fortalecimiento de la diversidad étnica y cultural. El objetivo es no solo posicionar al turismo comunitario en los diferentes sectores del Estado ecuatoriano a través de políticas públicas claras que motiven la inversión del Estado, sino generar una conciencia nacional e internacional de que experiencias como las que se vienen implementado van más allá de la simple oferta turística. Es una forma de vida con identidad, con responsabilidad, con conciencia y compromiso no solo con nuestras futuras generaciones, sino con la vida de todo el planeta.... La FEPTCE, debe brindar un modelo de desarrollo alternativo al de las comunidades indígenas y campesinas, que priorice la integridad cultural y natural del País por encima de la predominante "visón mercantilista de poder" (FEPTCE, 2017)

\section{Territorios para turismo comunitario}

En base al contexto teórico del TC se vuelve importante comprender el territorio rural partiendo desde: recursos, atractivos, productos y finalmente como destino considerando el espacio geográfico o lugar donde se establecen la mayor parte de relaciones o momentos de la verdad entre la oferta y demanda. (Velasquez Flores, 2014) \& (QuishpeQuishpe, 2019).

Figura 2. Relación entre el recurso, atractivo, producto y destino turístico comunitario, fases:

FASE II De atractivo > Producto

\section{FASEI De recurso > Atractivo}

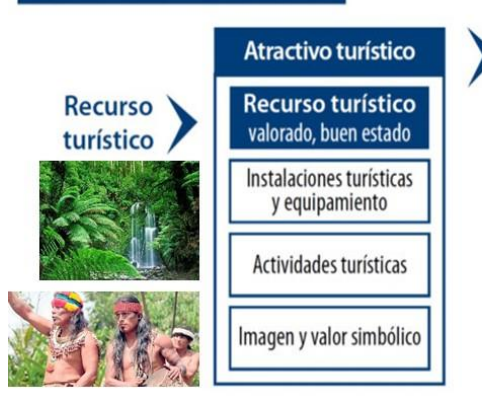

\section{Producto turístico}

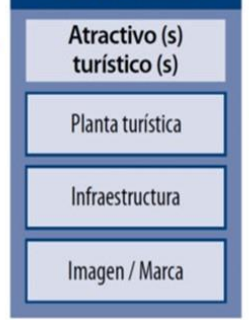

Imagen/Marca

\section{Destino, TC}

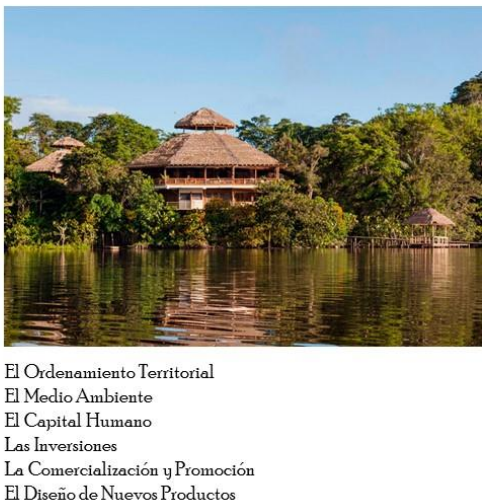

Fuente: Elaboración propia

\section{Modelos de gestión para el turismo comunitario}

Para definir a los modelos de gestión, en la actualidad se ha considerado cinco componentes clave y fundamentales; y, podrían ajustarse dependiendo del espacio 
geográfico y sus bondades. (Flores, 2014); (Mendoza-Torres \& Bayas-Escudero, 2018) \& (Quishpe-Quishpe, 2019)

- La caracterización sistémica del turismo

- La planificación turística

- La calidad turística

- La competitiva turística

- La sostenibilidad

Para la generación de los modelos de gestión turística, estos sistemas deben responder a una estructura planificada y organizada concreta; es así, que pueden existir en literatura y en la praxis, de acuerdo a los requerimientos de la estructura legal y giro de una empresaria. El ambiente legal de derecho privado son sociedades mercantiles, asociaciones civiles y comunitarias. Teniendo como objetivo un fin común, particular o general, direccionado al desarrollo económico organizacional con enfoque de bien común.

Luego de un análisis profundo del estado del arte y la praxis de diferentes organizaciones turísticas comunitarias, en esta ocasión evidenciaremos el modelo de gestión de turismos rural comunitario propuesto por la Fundación CODESPA. Donde indica, El turismo rural comunitario, es actualmente una gran oportunidad de desarrollo para las comunidades indígenas de escasos recursos ubicadas en zonas de alto potencial turístico, ya que les permite acceder a los beneficios que brindan las actividades económicas relacionadas con la actividad. Según la Organización Mundial del Turismo OMT, los países emergentes totalizaron más de 470 millones de llegadas internacionales el año pasado, lo cual convirtió a la actividad turística en uno de los primeros vehículos de generación de ingresos y empleos para estas economías muy vulnerables.

Figura 3. Modelo de gestión para turismo comunitario

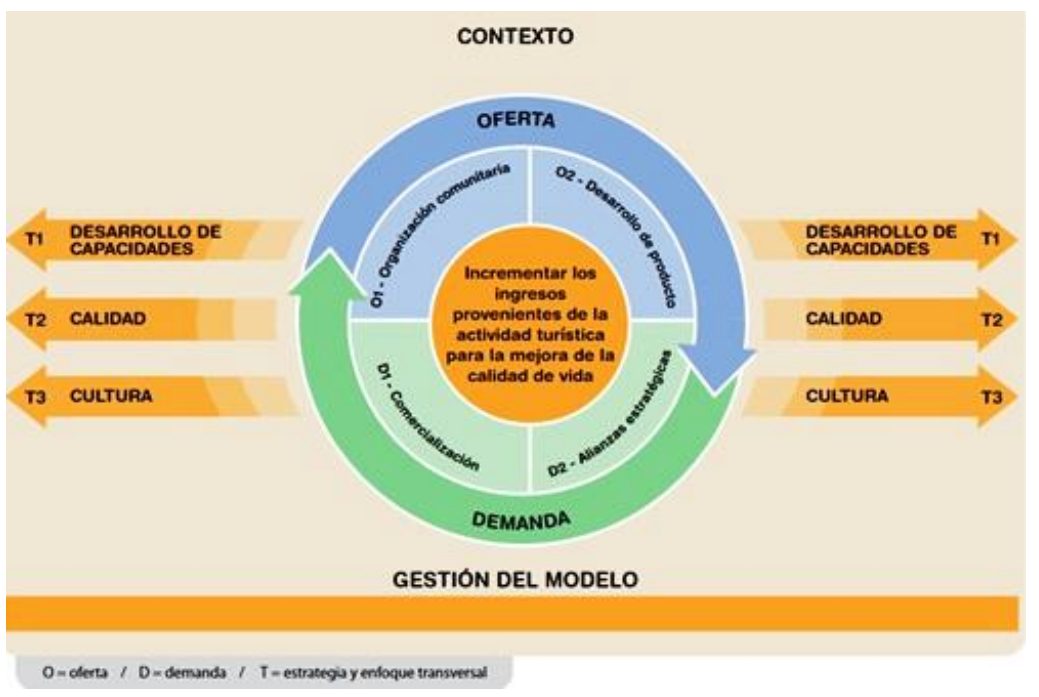

Fuente: Tomado de (CODESPA, 2011) \& (Quishpe-Quishpe, 2019). 
Las condiciones más básicas para la generación y operación de un modelo de gestión para el turismo comunitario en la etapa inicial pueden ser las siguientes:

Figura 4. Condiciones básicas, modelo de gestión para el turismo comunitario

1

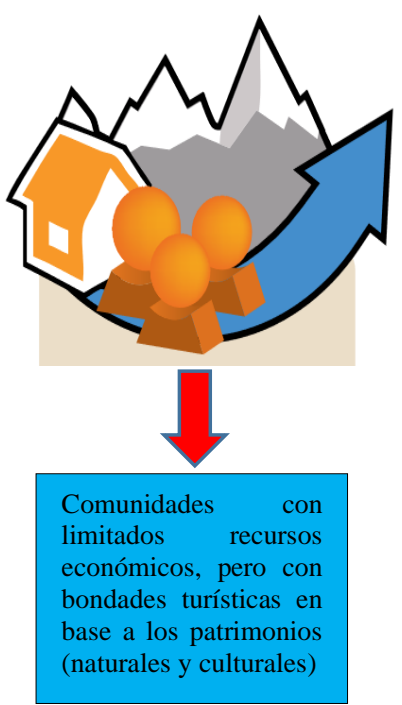

2

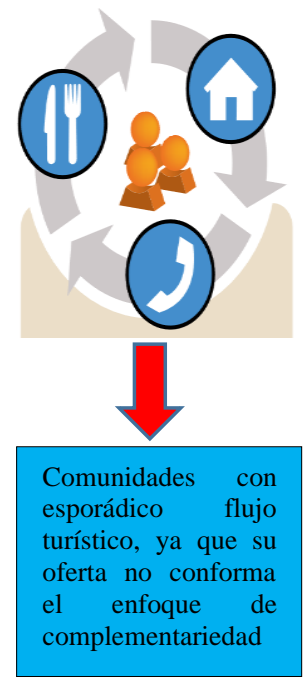

3

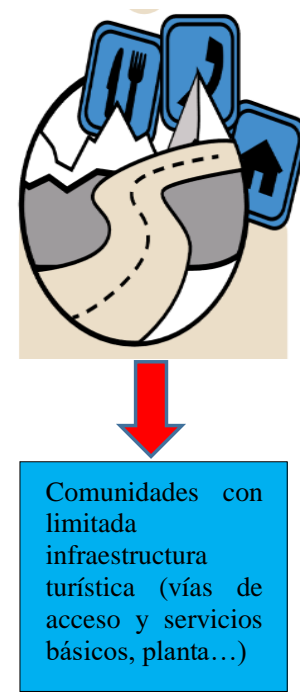

4

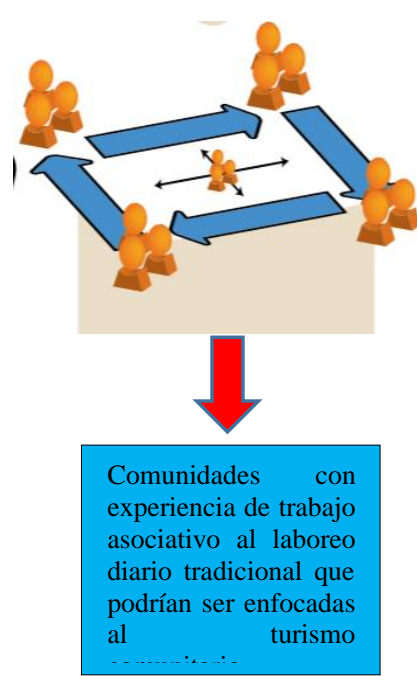

Fuente: Elaboración propia a partir de (CODESPA, 2011) \& (Quishpe-Quishpe, 2019).

La mayoría de los modelos de gestión, varían según la zona donde se ejecuta el turismo; en función de las variables legales, económicas, culturales, sociales, políticas y ambientales; siendo así, que el modelo pueda adaptar a las necesidades existentes en el territorio. Finalmente, un modelo debería exponer una metodología que garantice el manejo del turismo mediante un proceso de: planificación, organización, operación y valoración.

\section{Planteamiento metodológico}

La investigación se realizó en la provincia de Napo, cantón Archidona en sus parroquias rurales; Cotundo y Hatun Sumaco; como objeto practico, se constituyó en las comunidades Santa Rita, Amarun Pakcha y Sacha Wayusa, mismas que realizan turismo con enfoque TC. El procedimiento metodológico fue principalmente de carácter descriptivo - sintético. En base a los referenciados de (Avella, 2004); (Merinero \& Pulido, 2009); (Baptista, Collado, \& Samperi, 2010) (Plaza, 2013); (Campos \& González2015); (Reyes, Ortega, \& Machado, 2017); (Mendoza-Torres \& Bayas-Escudero, 2018) \& (Quishpe-Quishpe, 2019). 
Figura 5. Planteamiento metodológico

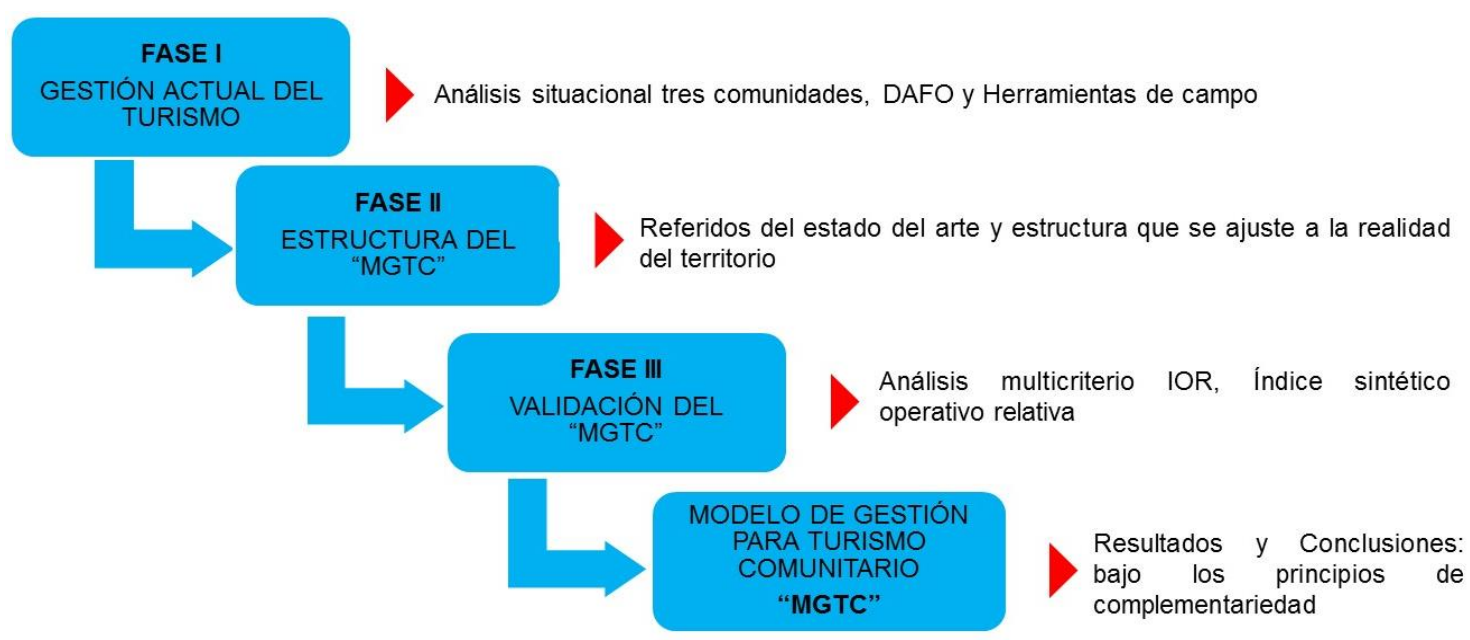

Fuente: Elaboración propia

\section{Fase I}

De acuerdo a los instrumentos necesarios se procedió a realizar un análisis DAFO (por componentes) en territorio, se aplicó en tres (3) comunidades Santa Rita, Amarun Pakcha y Sacha; a fin de conocer el estado real actual de la gestión que se está llevando en los lugares de interés turístico con aplicación al comunitarismo. Así, mismo se aplicó las matrices: matriz de evaluación de actores internos MEFI y matriz de evaluación de factores externos MEFE

\section{Fase II}

La estructuración de un modelo de gestión que responda a las necesidades territoriales turísticas de las tres (3) comunidades. Es así, que se generó un modelo de gestión para el turismo comunitario "MGTC" como resultado de un análisis de varios modelos existentes. Desarrollando así, una herramienta de planificación y mejora permanente las capacidades técnicas de los gestores.

\section{Fase III}

El modelo de gestión para turismo comunitario, fue validado por terceros (expertos) bajo el análisis mul-ticriterio del índice sintético de operatividad relativa "IOR". Información que direccionan a los resultados y conclusiones; $y$, la posible la aplicación de este nuevo modelo de gestión en territorio. Instrumento de capital importancia para el trabajo mancomunado bajo la responsabilidad de todos con un solo principio que es "complementariedad competitiva" en tiempos contemporáneos.

La selección de los expertos para la realización del análisis mul-ticriterio se estableció, como componente fundamental, por el grupo coordinador. Los quince (15) expertos que participaron en validación del "modelo", fueron escogidos por su experiencia y especialización en temas de turismo con enfoque comunitario; y, proceden de las áreas de investigación, planificación y gestión. (Espín, Ruiz \& Rodríguez, 2019). 
Tabla 2. Número de expertos y las áreas del conocimiento

\begin{tabular}{cl}
\hline No. Expertos & \multicolumn{1}{c}{ Áreas del conocimiento } \\
\hline 4 & Planificación turística local y regional y nacional \\
6 & Gestión de los Patrimonios \\
7 & Planificación urbana, peri urbana y rural \\
4 & Sector académico Planificación de la gestión turística. \\
8 & Turismo - planificación territorial \\
3 & Agrupaciones de prestadores de servicios turísticos \\
5 & Desarrollo sostenible. \\
\hline
\end{tabular}

*Cada experto aportó en más de un área del conocimiento.

Fuente: Elaboración propia

\section{Resultados}

En la actualidad el turismo comunitario, se asiste con un gran desarrollo a partir de clientes/turistas formados e informados, con criterios de protección y aprovechamiento adecuado de los patrimonios (natural y cultural) en territorios rurales. Reducto que las comunidades amazónicas están aprovechando para generar nuevas formas de laboreo con enfoque al vivir mejor toda una vida. La responsabilidad ulterior de los gestores turísticos en estos espacios, les conduce a generar economía sostenible propiciando una nueva forma de gestión que la llamaremos como: COMPLEMENTARIEDAD PARA EL TURISMO COMUNITARIO, paradigma novedoso para tiempos resilientes contemporáneos.

Para conocer la realidad turística de la zona de estudio se procedió a realizar la matriz DAFO, por componentes (endógeno y exógeno) herramienta para detallar las fuerzas, debilidades, oportunidades y amenazas; para el efecto, fueron ponderadas con criterios técnicos de rigor. Sin embargo, para sustentar de mejor manera, se realizó una contextualización de cada iniciativa turística.

\section{Santa Rita, CTC}

La comunidad Santa Rita, conocida actualmente como el Pueblo del Cacao y Chocolate, es una de los sectores desde donde se extrae el cacao fino de aroma que varias empresas nacionales y extranjeras están elaborando y exhibiendo los mejores productos.

Santa Rita es una comunidad de 700 habitantes, ubicada en las cercanías de la Reserva Ecológica Coloso Chalupas, a 15 minutos de la ciudad de Archidona, cuya economía se basa en la producción de cacao, guayusa, yuca, plátano, y otros productos agropecuarios propios de la zona. 
Una vez denominada esta comunidad como; el Pueblo del Cacao y Chocolate, se han construido facilidades para permitir a los visitantes/turistas conocer y vincularse en la gestión del cacao. Cuenta con servicios de alojamiento y alimentación, senderos para camitas, áreas de camping y más servicios turísticos. Su modelo de gestión comunitaria se sustenta básicamente en la propuesta "Tour del Chocolate" al que se acogen varias empresas de turismo nacional. Así mismo, se cuenta con facilidades para realizar eventos especializados como conferencias, talleres, capacitaciones...

\section{Amarun Pakcha, CTC}

Wawa Sumaco es una comunidad de alrededor de 950 habitantes localizada en la parroquia Hatun Sumaku, cantón Archidona, Napo, en la zona de amortiguamiento del Parque Nacional Sumaco. Desde el año 2011 realiza turismo como emprendimiento Amarun Pakcha "Cascada de la Anaconda" destacando actividades de naturaleza (senderismo, miradores...); cultura (petroglifos, chocolate y café artesanal); y gastronomía local. Sus activos son ríos, cascadas, grutas, cuevas, cavernas y bosque prístino.

Actualmente presta los servicios de: Alimentación con capacidad de 40 pax, áreas de camping, excursiones. La principal aventura es el recorrido hacia las cavernas del gallo de la peña que dura 6 hora, zona de petroglifos, bosques y paisajes aptos para la fotografía.

\section{Sacha Wayusa, CTC}

Es un emprendimiento de turismo comunitario que empezó hace cuatro años liderado por siete mujeres en la comunidad 9 de Julio, ubicada en Cotundo, en la ciudad de Archidona. La comunidad cuenta con un centro ceremonial donde los visitantes/turistas pueden disfrutar de un "demostración cultural", que incluye una muestra de danza, música con instrumentos que les provee la misma naturaleza, además de la explicación de "Guayusaupina" una costumbre Kichwa de toma de la guayusa en la madrugada, compartiendo sus sueños.

El emprendimiento cuenta con dos cabañas con una capacidad para 8 pax. Además, la alimentación es por encargo: el desayuno, almuerzo y merienda. La mayoría de alimentos son cosechados en sus parcelas de terreno y los platos son típicos de la zona. En la actualidad son 20 los socios de este emprendimiento.

Además, los habitantes realizan artesanías: pulseras, collares, llaveros, lanzas, cuchillos; suvenires, elaboradas con semillas, madera y recursos endémicos de la zona. 
Tabla 3. Ubicación de las comunidades en estudio

\begin{tabular}{cccc}
\hline NOMBRE DEL CTC & PARROQUIA & \multicolumn{2}{c}{ COORDENADAS } \\
\cline { 2 - 3 } & & LATITUD & LONGITUD \\
\hline CTC SANTA RITA & PARROQUIA & $0^{\circ} 52^{\prime} 25.16^{\prime \prime} \mathrm{S}$ & $77^{\circ} 49^{\prime} 46.36^{\prime \prime O}$ \\
& ARCHIDONA & & \\
CTC A MARUM & EN LA & $0^{\circ} 43^{\prime} 19.61^{\prime \prime S}$ & $77^{\circ} 34^{\prime} 37.73^{\prime \prime O}$ \\
PAKCHA & PARROQUIA & & \\
& HATUN SUMACO & \\
CTC SACHA WAYSA & EN LA & $0^{\circ} 49^{\prime} 12.94 " \mathrm{~S}$ & $77^{\circ} 48^{\prime} 51.25^{\prime \prime O}$ \\
& PARROQUIA & \\
& COTUNDO & & \\
&
\end{tabular}

Fuente: Elaboración propia

Tabla 4. Principales variables de la matriz DAFO

\begin{tabular}{|c|c|c|}
\hline \multirow[t]{2}{*}{ Debilidades } & D1 & $\begin{array}{l}\text { Modelo de gestión territorial, no se ajusta a la realidad } \\
\text { comunitaria actual }\end{array}$ \\
\hline & D2 & Limitada capacitación e innovación \\
\hline \multirow[t]{2}{*}{ Amenazas } & $\mathrm{A} 2$ & Esporádica inversión económica por parte de superestructura \\
\hline & $\mathrm{A} 2$ & $\begin{array}{l}\text { Soporte técnico, capacitación y promoción gubernamental es } \\
\text { limitado }\end{array}$ \\
\hline \multirow[t]{2}{*}{ Fortalezas } & $\mathrm{F} 1$ & Estructura organizativa comunitaria (empírica) \\
\hline & $\mathrm{F} 2$ & $\begin{array}{l}\text { Integración de los patrimonios a nuevas alternativas económicas } \\
\text { en su laboreo diario }\end{array}$ \\
\hline \multirow[t]{2}{*}{ Oportunidades } & O1 & $\begin{array}{l}\text { Interés de comunidades aledañas en participar en el TC con } \\
\text { enfoque de gestión complementariedad competitiva. }\end{array}$ \\
\hline & $\mathrm{O} 2$ & $\begin{array}{l}\text { Mercado actual con interés de productos turísticos comunitarios } \\
\text { con calidad y bio-seguros para todos }\end{array}$ \\
\hline
\end{tabular}

Fuente: Elaboración propia

Gráfico 2. Ponderación, MEFI

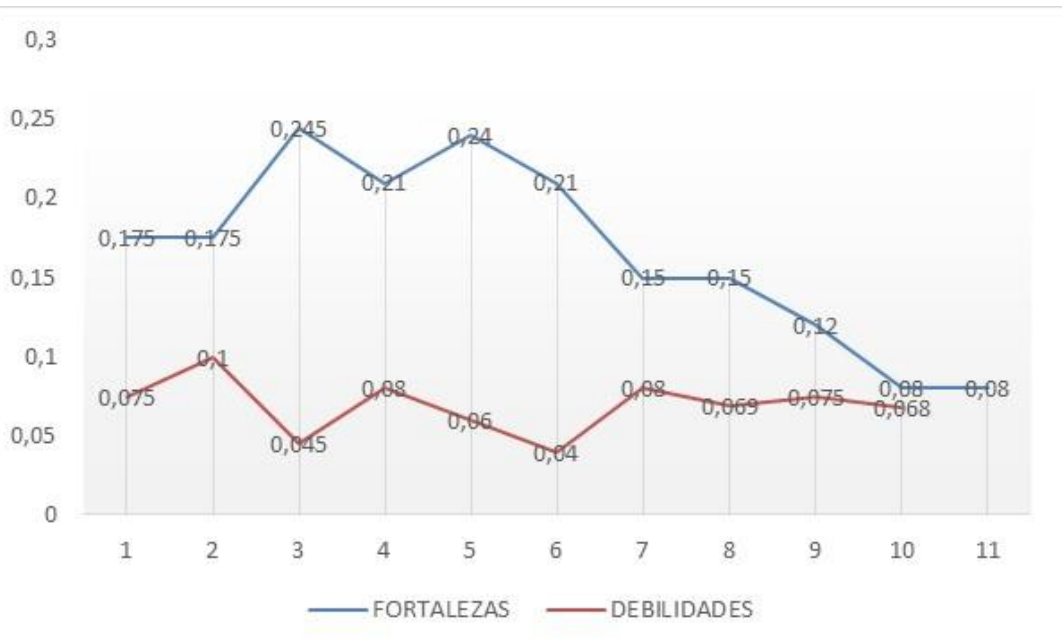

Fuente: Elaboración propia 


\section{Parámetros:}

$0.0=\sin$ importancia; $1,0=$ de gran importancia.

$1=$ debilidad importante; $2=$ debilidad menor;

$3=$ fortaleza menor; $4=$ fortaleza importante.

La realidad turística en la zona de estudio, a partir de análisis endógeno ponderado, de las tres (3) iniciativas de TC, arrojo un valor de 2,527 de la media nominal de 2.50, Evidenciando que poseen un margen poco significativo de fortalezas. Insumos para generar cambios a partir y tomar decisiones correctivas en beneficio del tejido social local en base a gestión comunitaria con enfoque de complementariedad.

\section{Gráfico 3. Ponderación, MEFE}

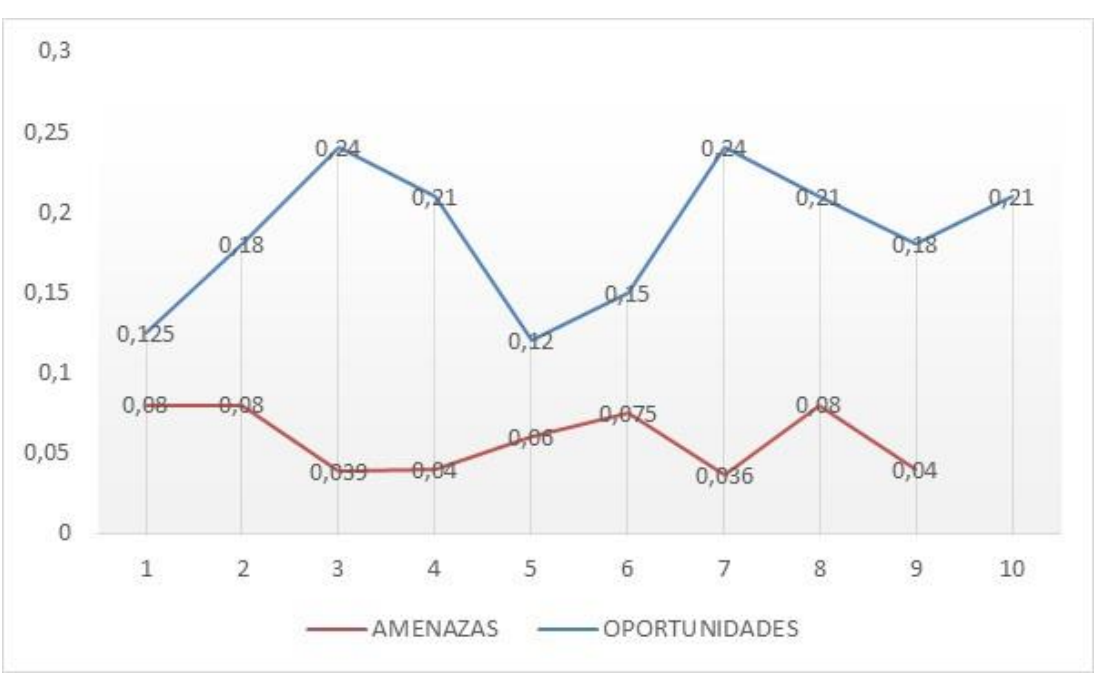

\section{Parámetros:}

\section{Fuente: Elaboración propia}

$0.0=\sin$ importancia; $1,0=$ de gran importancia.

$1=$ amenaza importante; $2=$ amenaza menor;

$3=$ oportunidad menor; $4=$ oportunidad importante.

El entorno exógeno, es sin duda un componente de capital importancia; a fin, de conocer acertadamente cada una de las amenazas y oportunidades que inciden directa o indirectamente en el accionar diario del TC. Luego de una exhaustiva lectura crítica, en referencia a los resultados ponderados, estos son: 2.53 sobre la media de 2.50; evidenciando que las oportunidades no son del todo relevantes; descifrando que, es necesario incluir el apoyo de las entidades gubernamentales a nuevas formas de gestión local como política territorial comunitaria articulada.

La producción y práctica de un modelo de gestión para el turismo comunitario con enfoque de complementariedad, debe contener los siguientes factores preliminares:

- Metodología técnica; planeación, organización, ejecución, operación y valoración; mismas, que deben ser generadas desde la territoriedad de las comunidades. 
- Conocer la realidad del territorio y patrimonios

- Articular la participación permanente de superestructura en territorio (política, ambiente legal, investigación y desarrollo)

- Direccionar el aprovechante racional de los recursos culturales, naturales, físicos y humanos con un enfoque de empresa comunitaria como parte de aldea global.

- Incluir irremediablemente un programa de monitoreo, seguimiento y evaluación en todos los componentes del TC.

- Toma de decisiones coyunturales, de acuerdo a las particularidades geográficas; así, ajustando la autogestión al bienestar social, estableciendo al turismo como parte del laboreo diario.

En este contexto se propone articular los tres centros de turismo comunitario; Santa Rita, Amarun Pakcha y sacha Waysa bajo un enfoque de Complementariedad; donde, cada comunidad oferta un producto estrella irrepetible en otro territorio. Originando un trabajo ordenado a partir de las variables que compone el modelo: Filosófico, Estratégico, Táctico Operativo y Valorativo. Herramienta capas operativizar esta modalidad turística en territorios comunitarios obedeciendo la trilogía básica de sostenibilidad y la salud de todos; y, aplicando de los principios de la Economía Popular y Solidaria.

Figura 6. Modelo de gestión propuesto

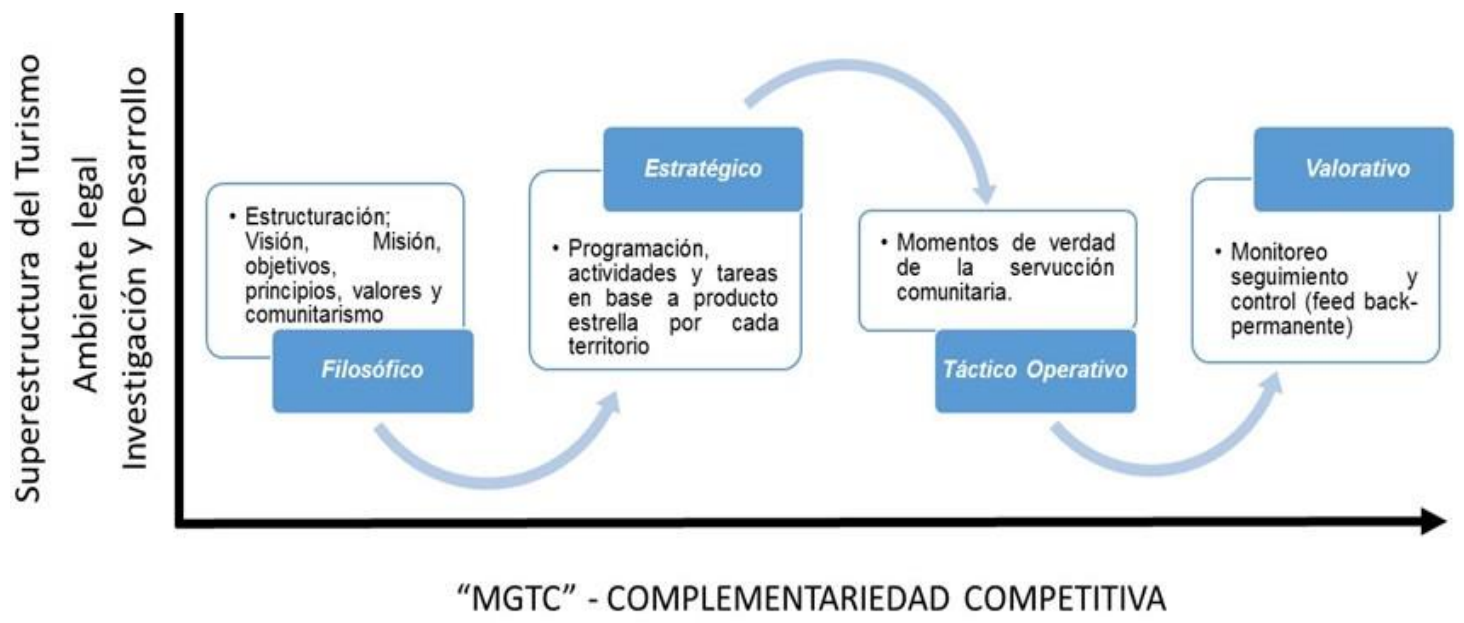

Fuente: Elaboración propia

La superestructura, organismos públicos y privados de apoyo a la actividad, serán quienes participen con el soporte legal, investigación y desarrollo en el área capacitación, mercadeo y generación de productos turísticos complementarios en otros territorios como en las comunidades en estudio. 
La variable filosófica obedece a la fundamentación teórica principalmente de la planificación sustentado en la concepción del territorio, los patrimonios natural y cultural. Es fundamental para producir comunitarismo institucionalizado, organización social, práctica individual y colectiva; permitiendo, una nueva forma de generar territoriedad técnica y metodológica local.

La estrategia, constituye en la variable de la organización de las actividades generales hasta las tareas puntuales y la como ejecutarlas. Además, cuenta con factores clave que delimitan cada uno de los productos de cada territorio (estrella), siendo único e irrepetible en otro lugar, para ello contiene componentes como: auto-organización, articulación glocal (desde lo local a lo global), El cómo de la auto-gestión (costes y beneficios de la actividad en la zona) y finalmente la complementariedad con acción colectiva (sostenibilidad)

Lo táctico operativo, hace referencia a los llamados momentos de verdad del turismo en cumplimento a los objetivos concretos establecidos en las variables mencionadas. Espacio que el modelo evidencia ser una herramienta útil para la actividad y la servucción comunitaria, permitiendo que cada comunidad se ajuste con su realidad a la modalidad del denominado turismo comunitario en la praxis.

Finalmente, la valoración en un reducto que en la actualidad ninguna empresa, emprendimiento o comunidad que realiza turismo debe dejar de practicar, ya que el monitoreo diario, seguimiento semanal o mensual y evaluación final contienen indicadores del avance o limitación del modelo. Herramientas que deben ser planeas, organizadas y ejecutadas de acuerdo con las aptitudes de los gestores locales.

Las relaciones que deben existir para que el modelo se establezca en el territorio y tenga la funcionalidad en la práctica; como se indicó, se debe realizar circuito turístico con enfoque de complementariedad competitiva, generando servicios únicos en cada comunidad y estos sean parte de un solo producto como lo indica la figura 7. Esto podría asegurar la continuidad permanente de trabajo conjunto con eficiencia colectiva y participación de todos los actores y gestores.

El modelo de gestión, fue sometido a la validación por terceros (expertos) ver cuadro 2., bajo el análisis mul-ticriterio en base al índice sintético de operatividad relativa "IOR". Los sujetos expuestos a la valoración no recibieron información completa del estudio, sino más bien enfocando directamente el procedimiento propuesto y las variables, que mediante puntuaciones de relevancia, efectividad y factibilidad evidenciaron la pertinencia, innovación y actualidad de la herramienta en referencia a tiempos actuales de resiliencia de la actividad en medio de un factor exógeno de peligro. (Coll-Serrano, Blasco-Blasco, Carrasco-Arroyo, \& Vila-Lladosa, 2017); (Espín, Ruiz, \& Rodríguez, 2019) 
Dónde: los criterios de relevancia, especificad y factibilidad: $\mathrm{wR}, \mathrm{wE}$ y $w F$ denotan las ponderaciones o pesos respectivos de cada criterio en el índice (Grandzol \& Gershon,1994); (Tague, 2014); (Espín, Ruiz, \& Rodríguez, 2019), que inicialmente han sido prefijadas a los valores de las puntuaciones dadas por los expertos $(\mathrm{w} R=0,5 ; \mathrm{wE}$ $=0,25$ y wF=0,25).

- Relevancia. - Grado de importancia y utilidad que tiene el "modelo" para medir potencialmente el fenómeno observado, posibilitando la toma de decisiones por parte del gestor.

- Especificidad. - En qué medida el "modelo" responde efectivamente a variaciones del fenómeno observado y su variación.

- Factibilidad. - Posibilidad de fijar un valor deseado "modelo", es decir, en qué medida es posible asignar un objetivo cuantificable para ser puesto en operación.

El modelo de gestión para el para los centros de turismo comunitario del cantón Archidona con enfoque de complementariedad competitiva, recibieron las siguientes valoraciones:

Tabla 5. Puntuación del IOR, Modelo de gestión

\begin{tabular}{|c|c|c|c|c|c|c|c|}
\hline Componente & Variables & No & item & $\mathbf{w} \mathbf{R}$ & $\mathbf{w} \mathbf{E}$ & $\mathbf{w} \mathbf{F}$ & IOR \\
\hline \multirow{7}{*}{ 赵 } & \multirow{3}{*}{$\begin{array}{c}\text { Superestructura } \\
\text { del Turismo }\end{array}$} & 1 & $\begin{array}{l}\text { Trabajo articulado en } \\
\text { territorios comunitarios } \\
\text { (inversión económica) }\end{array}$ & 0,48 & 0,22 & 0,24 & 0,94 \\
\hline & & 2 & $\begin{array}{l}\text { Apoyo planificado en } \\
\text { capacitación turística } \\
\text { con enfoque de gestión } \\
\text { comunitaria }\end{array}$ & 0,4 & 0,21 & 0,23 & 0,84 \\
\hline & & 3 & $\begin{array}{l}\text { Apoyo planificado en } \\
\text { programa de marketing } \\
\text { turístico comunitario }\end{array}$ & 0,47 & 0,24 & 0,23 & 0,94 \\
\hline & \multirow{3}{*}{ Ambiente Legal } & 4 & $\begin{array}{l}\text { Aporte de la Ley } \\
\text { Amazónica "CTEA" al } \\
\text { turismo }\end{array}$ & 0,37 & 0,19 & 0,21 & 0,77 \\
\hline & & 5 & \begin{tabular}{lr}
\multicolumn{2}{l}{ Regulación y control por } \\
parte de entes \\
gubernamentales \\
asociativos
\end{tabular} & 0,41 & 0,2 & 0,19 & 0,8 \\
\hline & & 6 & $\begin{array}{l}\text { Planificación territorial } \\
\text { en base competencias del } \\
\text { COOTAD }\end{array}$ & 0,48 & 0,23 & 0,24 & 0,95 \\
\hline & $\begin{array}{c}\text { Investigación y } \\
\text { desarrollo }\end{array}$ & 7 & $\begin{array}{l}\text { Generación de programa } \\
\text { de investigación y } \\
\text { desarrollo en el área de la } \\
\text { cultura, ambiente y } \\
\text { servicios turísticos como } \\
\text { herramientas de } \\
\text { desarrollo de turismo } \\
\text { comunitario }\end{array}$ & 0,47 & 0,24 & 0,24 & 0,95 \\
\hline
\end{tabular}




\begin{tabular}{|c|c|c|c|c|c|c|}
\hline \multirow{10}{*}{$\begin{array}{l}\text { Estructuración } \\
\text { filosófica }\end{array}$} & 8 & $\begin{array}{l}\text { Estructuración; Visión, } \\
\text { Misión, Valores, } \\
\text { Principios, Objetivos,... }\end{array}$ & 0,48 & 0,23 & 0,25 & 0,96 \\
\hline & 9 & $\begin{array}{l}\text { Zonificación del } \\
\text { territorio y patrimonios } \\
\text { en base al uso actual y } \\
\text { potencial (laboreo diario } \\
\text { y turismo) }\end{array}$ & 0,47 & 0,24 & 0,24 & 0,95 \\
\hline & 10 & $\begin{array}{l}\text { Organización } \\
\text { comunitaria formal con } \\
\text { enfoque de asociatividad }\end{array}$ & 0,48 & 0,25 & 0,22 & 0,95 \\
\hline & 11 & $\begin{array}{l}\text { Acuerdos para generar } \\
\text { un productos estrella y } \\
\text { secundarios en cada } \\
\text { CTC }\end{array}$ & 0,49 & 0,24 & 0,25 & 0,98 \\
\hline & 12 & $\begin{array}{l}\text { Auto-organización } \\
\text { gestión en función de } \\
\text { costes y beneficios del } \\
\text { turismo comunitario por } \\
\text { CTC y colectivo }\end{array}$ & 0,46 & 0,23 & 0,24 & 0,93 \\
\hline & & $\begin{array}{l}\text { Gestión del turismo } \\
\text { comunitario }\end{array}$ & & & & \\
\hline & 13 & $\begin{array}{l}\text { "complementario } \\
\text { competitivo", como } \\
\text { circuito turístico abierto }\end{array}$ & 0,5 & 0,24 & 0,25 & 0,99 \\
\hline & & Momentos de verdad en & & & & \\
\hline & & referencia a los & & & & \\
\hline & 14 & $\begin{array}{l}\text { productos y servicios } \\
\text { ofertados en función de } \\
\text { un orgánico funcional }\end{array}$ & 0,5 & 0,25 & 0,25 & 1 \\
\hline \multirow[t]{6}{*}{$\begin{array}{l}\text { Táctico } \\
\text { operativo }\end{array}$} & & $\begin{array}{l}\text { Turismo comunitarios } \\
\text { como parte del laboreo }\end{array}$ & & & & \\
\hline & 15 & $\begin{array}{l}\text { diario de los habitantes } \\
\text { de la comunidades y } \\
\text { CTC }\end{array}$ & 0,49 & 0,24 & 0,25 & 0,98 \\
\hline & 16 & $\begin{array}{l}\text { Valoración del } \\
\text { patrimonio cultural local }\end{array}$ & 0,47 & 0,23 & 0,24 & 0,94 \\
\hline & & $\begin{array}{l}\text { Programa de monitoreo, } \\
\text { seguimiento }\end{array}$ & & & & \\
\hline & 17 & $\begin{array}{l}\text { evaluación a partir del } \\
\text { cumplimento }\end{array}$ & 0,48 & 0,22 & 0,25 & 0,95 \\
\hline & & $\begin{array}{l}\text { actividades } \\
\text { responsables }\end{array}$ & & & & \\
\hline \multirow{3}{*}{ Valoración } & 18 & $\begin{array}{l}\text { Verificación permanente } \\
\text { del modelo de gestión }\end{array}$ & 0,46 & 0,21 & 0,24 & 0,91 \\
\hline & 19 & $\begin{array}{l}\text { Programa ajustado a la } \\
\text { realidad y aptitud de los } \\
\text { gestores locales }\end{array}$ & 0,47 & 0,24 & 0,24 & 0,95 \\
\hline & & Valoración & 0,46 & $\mathbf{0 , 2 3}$ & $\mathbf{0 , 2 4}$ & $\mathbf{0 , 9 3}$ \\
\hline
\end{tabular}

Fuente: Elaboración propia

Parámetros interpretación:

1.- $0,1-0,25=$ No Aplica

3.- $0,51-0,75=$ De Aplicación moderada
2.- $0,26-0,50=$ De Aplicación baja

4.- $0,76-1=$ De Aplicación alta 
La valoración final del "IOR", determino que existe una coincidencia casual alta entre los expertos consultados valor que evidencian técnicamente que es posible la aplicación de este modelo de gestión en territorio.

\section{Conclusiones}

- Con la metodología aplicada, permitió conocer los propuestos teóricos presente en el estado del arte y la realidad de los centros turísticos comunitarios tres (3) Santa Rita, Amarun Pakcha y Sacha Wayusa, identificado la situación de la gestión turística de los gestores comunitarios. Se evidencia que estas comunidades poseen en sus territorios una gran cantidad de recursos naturales y culturales, que de alguna forma los han convertido en atractivos turísticos, mismos son gestionados a partir del conocimiento empírico de los gestores turísticos locales.

- La modalidad de turismo comunitario posee un espectro importante para desarrollarse de forma sostenida; sin embargo, los tres centros turísticos poseen un valor ponderado Endógeno MEFI de 2,52 y Exógeno MEFE de 2.53 reclacando que el valor dela media es de 2.50 de acuerdo a las variables de la matriz DAFO. Datos que comprueban un margen poco significativo de fortalezas, y las oportunidades no son del todo relevantes, evidenciando de forma técnica que el modelo de gestione actual para estos espacios de uso turístico no se ajustan al escenario vigente del turismo.

- La propuesta del modelo de gestión con enfoque de complementariedad vincula a la sostenibilidad turística comunitaria en el Catón Archidona; herramienta, que puede contribuir a superar las limitaciones comunitarias / Turísticas. Originando un trabajo ordenado a partir de las variables que compone el modelo: Filosófico, Estratégico, Táctico Operativo y Valorativo. Instrumento que podría facilitar su utilización prácmatica desde la estructura comunal y los rasgos distintivos organizacionales territoriales.

- En base a las valoraciones de los expertos sobre el modelo de gestión turística comunitaria (MGTC) con enfoque de complementariedad de acuerdo a las bondades de cada territorio. Determino: la valoración ultima del IOR es del 0.93 afirmando que es "De Aplicación alta".

\section{Referencias Bibliográficas}

Asamblea General de las Naciones Unidas. (21 - 23 de June de 2017). Measuring Sustainable Tourism: A Call for Action - Report of the 6th International Conference on Tourism Statistics, Manila, Philippines, $N^{o}$ of Pages: 50. Obtenido 
de ISBN 978-92-844-1895-4, Digital; ISBN 978-92-844-1894-7, Impreso.: http://statistics.unwto.org/fr/node/48735

Barómetro OMT. (2020). Llegadas de turistas internacionales destinos La Américas. Obtenido de https://www.unwto.org/es/taxonomy/term/347

Blasco-Blasco, O., \& Coll Serrano, V. (2016). Selección de indicadores basada en métodos de optimización multicriterio una aplicación a la estrategia de cultura y desarrollo de España. Obtenido de Rect@: Revista Electrónica de Comunicaciones y Trabajos de ASEPUMA, Vol. 17, No. 12, págs. 19-33: https://dialnet.unirioja.es/servlet/articulo?codigo $=6466464$

Boussut et Elodie Salin, V. A. (2018). El turismo en las Américas: territorios, experiencias y ¿nuevos desafios? Obtenido de Ideas OpenEdition Journals: https://doi.org/10.4000/ideas.5721

Cabello, J. (2013). Synthetic indicators of mutual funds' environmental responsibility: 236, 313-325. Obtenido de An application of the Reference Point Method. European Journal of Operational Research: http://www.sciencedirect.com/science/article/pii/S03772

Camacho-Rui, E., \& Carrillo, A. (2016). Indicadores de sostenibilidad para el ecoturismo en Méxic. Recuperado el marzo de 2017, de Estado actual: http://www.scielo.org.mx/scielo.php?script=sci_arttext\&pid=S1665$80272016000100011 \& \operatorname{lng}=\mathrm{es} \& \operatorname{tlng}=\mathrm{es}$.

CODESPA. (2011). Modelo de gestión del turismo rural comunitario de CODESPA. Obtenido de UNA EXPERIENCIA REGIONAL ANDINA: https://www.codespa.org/app/uploads/modelo-gestion-turismo-ruralcomunitario.pdf

Coll-Serrano, V., Blasco-Blasco, O., Carrasco-Arroyo, S., \& Vila-Lladosa, L. (2017). Un sistema de indicadores para el seguimiento y evaluación de la gestión sostenible del turismo comunitario. Obtenido de Transinformação, 25(1), 55-63.: https://dx.doi.org/10.1590/S0103-37862013000100006

Espín Ortíz, C. G., Ruiz Marmol, E. E., \& Rodríguez Rodríguez, J. L. (2019). Propuesta, indicadores vinculados a la sostenibilidad turística en Pastaza, Ecuador. Obtenido de Ciencia Digital, 3(4.1), 21-38. https://doi.org/10.33262/cienciadigital.v3i4.1.972

Espin, C. (2019). Sistema de indicadores para el Turismo Sostenible, Pastaza; Tesis Doctoral Universidad de La Habana. La Habana, Cuba.

FEPTCE. (2006). Guía de Turismo Comunitario .

FEPTCE. (2012). Guía de Turismo Comunitario. 
FEPTCE. (2017). Federación Plurinacional de Turismo Comunitario del Ecuador. Obtenido de https://www.equatorinitiative.org/wpcontent/uploads/2017/05/case_1_1363900152.pdf

FEPTCE. (2017). Guía de Turismo Comunitario.

Figueroa Pinedo, J. (2014). Turismo comunitario, pobreza y desarrollo sostenible. Obtenido de https://core.ac.uk/reader/132555700

Gascón, J., \& Cañada, E. (2005). Viajar a todo tren: Turismo, desarrollo y sostenibilidad. Icaria. 2005. ISBN 84-7426-806-0.

Hechavarria, L. (2016). Best practices in tourist destinations sustainable development assessment: a literature review. Turismo. Estudos\&Práticas (RTEP/UERN), Mossoró/RN, vol. 5, n. 2, 149-185 (Vol. vol. 5).

Instituto Ecuatoriano de Estadística y Censos INEC. (3 de junio de 2017). Instituto Ecuatoriano de Estadística y Censos. Obtenido de http://www.ecuadorencifras.gob.ec/estadisticas/

Maldonado, C., \& Hernadez, G. (2017). Autogestión de sostenibilidad en destinos turísticos comunitarios . https://www.ilo.org/wcmsp5/groups/public/---americas/--ro-lima/documents/publication/wcms_185024.pdf.

Mendoza-Torres, M., \& Bayas-Escudero, J. (2018). Modelo de gestión para el turismo rural en la zona centro de Manabí, Ecuador. Escenario de las Ciencias, 5.

Mielke, E. J., \& Sperandio, D. (2009). Desarrollo turístico regional. El diagnóstico estratégico participativo ponderado - DEPP, aplicaciones y retos a la planificación turística". Anais do VI Seminário da Associação Naciona de Pesquisa e Pós-Graduação em Turismo - ANPTUR, São Paulo.

Ministerio de turismo. (Abril de 2020). Turismo en Cifras. Obtenido de servicios.turismo.gob.ec: https://servicios.turismo.gob.ec/turismo-cifras

Moragues Cortada, D. (2006). TURISMO, CULTURA Y DESARROLLO. Obtenido de https://www.oei.es/historico/cultura/turismodmoragues.htm

National Geographic. (25 de marzo de 2017). National Geographic. Obtenido de http://www.nationalgeographic.com.es/

OMT. (5 de mayo de 2015, 2018). Organización Mundial de Turismo. Obtenido de http://www2.unwto.org/es: http://www2.unwto.org/es

ONU. (2015). La Asamblea General adopta la Agenda 2030 para el Desarrollo Sostenible.

Obtenido

de https://www.un.org/sustainabledevelopment/es/2015/09/la-asamblea-generaladopta-la-agenda-2030-para-el-desarrollo-sostenible/ 
ONU. (07 de Octubre de 2017). Organización de las Naciones Unidas [en línea]. New York: La agenda de Desarrollo Sostenible. Obtenido de https://www.un.org/sustainabledevelopment/es/development-agenda/.

Ordóñez, E. F., Auquilla, L. A., Fernández, L., \& Sancho, D. (2016). Dinamización del turismo comunitario en la Amazonía Ecuatoriana. TURyDES Vol, 9 No. 20 Junio, 5.

Palafox, A., \& Anaya, J. (2017). Reflexiones en torno a la implementación de la agenda 21 en Cozumel. Obtenido de Gestión Turística, 7, 103-128: https://scholar.google.com/scholar?q=Gesti\%C3\%B3n+Tur\%C3\%ADstica\%2C $+7 \% 2 \mathrm{C}+103-128 . \& \mathrm{btnG}=\& \mathrm{hl}=$ es\&as_sd

Quishpe-Quishpe, A. A. (2019). DISEÑO DE UN MODELO GESTIÓN TURÍSTICOPARA INICIATIVAS DE TURISMO COMUNITARIO. Obtenido de http://dspace.udla.edu.ec/bitstream/33000/11160/1/UDLA-EC-TIAEHT-201929.pdf

Reguant-Álvarez, M., \& Torrado-Fonseca, M. (2016). El método Delphi . REIRE Revista d'Innovación, DOI: 10.1344/reire2016.9.1916, 87-102.

Reyes, M. V., Ortega, A. F., \& Machado, E. L. (2017). MODELO PARA LA GESTIÓN INTEGRADA DEL TURISMO COMUNITARIO ENECUADOR, CASO DE ESTUDIO PASTAZA. REVESCO, Revsita de Estudios Corporativos, Num. 123, 255. 256.

Rodriguez, D., \& Alavarez, J. (2013). Vulnerabilidad del turismo y comunicación institucional ante desastres. Estudio de caso, 15.

Sancho Pérez, A., \& García Mesanat, G. (29 de Mayo de 2019). ¿Que indica un indicador? Análisis comparativo en los destinos turísticos. Obtenido de Revista de análisis turístico, ISSN 2254-0644.: https://aecit.org/jornal/index.php/AECIT/article/view/90

Sanda , L. M., \& Rojas , D. (2020). Estrategias para el desarrollo del turismo Slow en el Ecuador. Puyo: Universidad Estatal Amazónica.

Shiguango, L. (2020). Modelo de Gestión para el Turismo Comunitario, Archidona. Proyecto de investigación de Maestria en Turismo, Mención: Gestión del Turismo, 6.

Sociedad de la Cultura. (2013). Cultura y Turismo: Factores del desarrollo económico y social. Buenos Aires, Argentina.: Secretaria de Cultura de la presidencia de la Nación. Obtenido de https://issuu.com/secretariadecultura/docs/cultura_y_turismo 
US Travel Association, 2018. (s.f.). U.S. states and cities attract more visitors, their local economies thrive. Obtenido de https://www.ustravel.org/issues/travel-promotion

Vargas-Cumbajín, C., Yánez-Sego, S., Hernadéz-Benalcázar, H., Méndez-Játiva, J., \& Valdiviezo-Leroux, W. (2019). La situación del turismo comunitario en Ecuador. Dominio de las ciencias, Dom. Cien., ISSN: 2477-8818, http://dx.doi.org/10.23857/dom.cien.pocaip.2017.4.1.enero.80-101. Obtenido de Do.

Velasquez Flores, M. (2014). Turismo comunitario. La representación de la cultura en escenarios turísticos: Estudio de caso: Comunidad Challapampa - Isla del Sol. Obtenido de RI-UMSA: http://repositorio.umsa.bo/xmlui/handle/123456789/15628 


\section{PARA CITAR EL ARTÍCULO INDEXADO.}

Shiguango Shiguango, L. D., Espín Ortíz, C. G., Olivo Pesántez, J. J., \& Pinta Rodríguez, M. I. (2021). Modelo de gestión para los centros de turismo comunitario del cantón Archidona. Explorador Digital, 5(2), 74-100. https://doi.org/10.33262/exploradordigital.v5i2.1655

\section{Ciencia}

El artículo que se publica es de exclusiva responsabilidad de los autores y no necesariamente reflejan el pensamiento de la Revista Explorador Digital.

El artículo queda en propiedad de la revista y, por tanto, su publicación parcial y/o total en otro medio tiene que ser autorizado por el director de la Revista Explorador Digital.
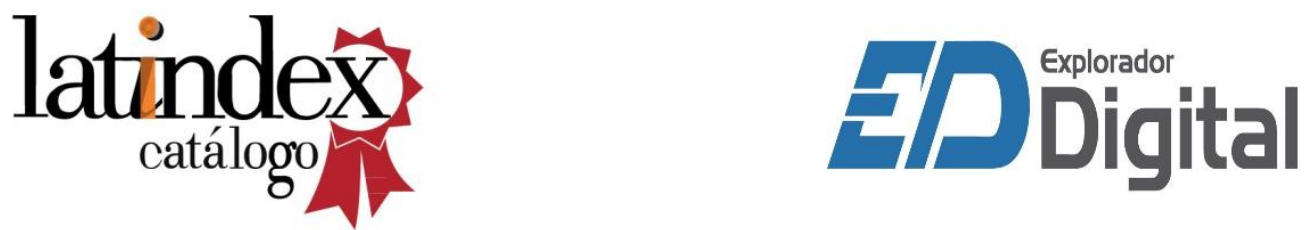